\title{
LXX. On some new cases of voltaic action, and on the construction of a battery without the use of oxidizable metals
}

\section{Alexander R. Arrott Esq.}

To cite this article: Alexander R. Arrott Esq. (1843) LXX. On some new cases of voltaic action, and on the construction of a battery without the use of oxidizable metals, Philosophical Magazine Series 3, 22:147, 427-434, DOI: 10.1080/14786444308636412

To link to this article: http://dx.doi.org/10.1080/14786444308636412

曲 Published online: 01 Jun 2009.

Submit your article to this journal $₫$ 
When distilled, the tannin gave no indication either of pyrogallic acid or of pyrocatechin.

Catechin, which is the part of catechu insoluble in cold water, when distilled, yielded the pyrocatechin of $Z$ wenger in considerable quantity. So far as I examined it, pyrocatechin appeared to possess the properties ascribed to it by that chemist.

In conclusion, I may mention that this is only the first of a series of papers on the astringent substances.

Glasgow, Oct. 26, 1842.

LXX. On some nere Cases of Voltaic Action, and on the Construction of a Battery roithout the use of Oxidizable Metals. By Alexander R. Arrott, Esq**

HAVING been for some time engaged in examining into certain remarkable voltaic actions occurring in cases hitherto unobserved, or at least not followed out so fully as their importance seems to demand, I am induced brietly to communicate the results of my inquiries, hoping they may not prove uninteresting to the Society.

It is a fact known to every one who has carefully observed the phænomena attending chemical decomposition by means of electricity, that the electrodes immersed in the solution undergoing decomposition, acquire the power of producing a current in the opposite direction to that previously passing through them, when they are made to touch each other without being removed from the liquid.

This effect has generally been ascribed to a power supposed to be acquired by the metals, of producing a current independently of any action of the liquids beyond that of simply completing the circuit, and has been called "polarization of the electrodes."

Becquerel was the first who advanced the opinion, that the effect was due to the alteration produced in the liquid by the current causing decomposition. He supposed that the current was a consequence of the combination of the acid and alkaline produced at the positive and negative surfaces; but it will be found that the most powerful acids and alkalies are incapable of producing a current, unless they readily undergo some other change than that which takes place when an acid and alkali combine as such. It has often been shown, that sulphuric acid and potash, for example, are nearly or altogether

* Communicated by the Chemical Society; having been read November 15,1842 . 
incapable of producing this effect; iodic, chloric, chromic, or, as in the beautiful arrangement of Becquerel, nitric acid, with an alkali, produce a powerful current, but in these cases the action is very different from that which takes place in simple neutralization of an acid by an alkali.

I have observed, that a current is produced in many cases where, from the nature of the liquids, no current can be supposed to arise either from the union of an acid and an alkali, or from the action of the liquids on the metals employed. Thus I found, that solutions of a per- and protosalt of iron, produced a current when they were allowed to touch each other, and also made to communicate by means of platina; the persalt becoming deoxidized and the protosalt oxidated.

It seemed that in this case the current was due to the oxidation and deoxidation of the liquids, by means of the elements of water which was decomposed, and it appeared probable that, if substances were used capable of exerting a greater attraction for the oxygen and hydrogen, a proportionally greater effect would be obtained. With this view, I tried solution of chlorine, and found that the effect was very much increased. I next tried iodine in solution in water, and also in iodide of potassium : the effect was very feeble; and this is exactly what we ought to expect, for iodine has nearly an equal tendency to unite with oxygen and hydrogen, as appears from the mode in which it decomposes water. I was not aware at the time of making these experiments, that Schoenbein had obtained the current from chlorine.

We have an extremely simple and beautiful illustration of these actions in the case of salts of iron. If two tubes be stopped at one end with plaster of Paris, and filled one with per- and the other with protosulphate of iron, and both immersed in a vessel containing dilute sulphuric acid, on adding red prussiate of potash to the persalt, and sulphocyanide of potassium to the other, no change takes place; but if we connect the two solutions by means of a slip of platina foil, we have instantly indications of the oxidation of the one, and deoxidation of the other. I have also constructed an apparatus in the form of a battery, which, while it serves to illustrate the action in question, may, I think, prove both convenient and economical as an instrument of research in ordinary galvanic experiments. It consists of six small circular jars, within which are fixed tubes of baked clay, or porous earthenware. Small cylinders of platina foil, 0.6 th inch diameter, and 1.5 inch long, were placed in the porous tubes, and outside these larger cylinders of 1.8 th inch diameter, and 1.5 th inch long. The whole was then formed into a series, by connecting the 
outer cylinder of the first jar with the inner one of the second, and so on; the porous tube was then filled with strong nitric acid, and the jar with solution of sulphuret of potassium. The arrangement is exactly similar to Daniell's constant battery, except that the metallic surfaces are entirely of platina.

With an instrument of the above dimensions, I have obtained by means of a voltameter, 0.5 th cubic inch of the mixed gases in a minute, and that action continues for some hours, with very little diminution.

I find that the substances capable of producing a current in similar circumstances, are very numerous; for example, perand protosalts of iron, tin, and manganese, an alkaline sulphuret hyposulphite, hypophosphite or a hydracid on the one side, and chlorine or chromic or nitric acid on the other.

The intensity of the effect is, however, very various in these different combinations; thus, with salts of iron it is very feeble; while with chlorine or nitric acid and an alkaline sulphuret, the intensity is such, that the induction of one pair of plates is sufficient to cause the decomposition of water.

Each of the combinations, it will be observed, is formed of an oxidating and a deoxidating substance, and the change which takes place is similar in all of them; the oxidating substance is reduced and the deoxidating is oxidated.

If we employ only one substance, for example-chlorine, the chlorous element of the water finding nothing with which it can unite, is evolved; but in that case the intensity of the action is very much reduced.

The mode in which the experiments were performed was very simple. A small vessel of baked clay was cemented inside a wine glass; the respective liquids were then poured into this vessel and into the glass, till they stood at the same level ; in this way they were in free liquid contact, while their actual mixture proceeded with extreme slowness; metallic plates, which were in all cases of platina, were then plunged into the solutions; the plates had been carefully cleaned with nitric acid, then with potash, and washed with water.

I now proceed to state the conclusions at which I have arrived, as regards the law which regulates the action in the ordinary voltaic battery, and in the arrangements above mentioned.

This I find to be in strict agreement with that of ordinary mechanical forces, viz. that the action and reaction are equal and opposite. When a metal is reduced from its solution, the equal reaction seems to follow as a corollary to the law of definite electrolyzation, and in cases where no solid substance is deposited, the same law holds. 
In order to prove this, and also to show that the effect is not dependent on any particular state of the metals, a porous vessel was filled with a mixture of strong solutions of protoand per-sulphates of iron; this vessel was then placed in another filled with the same mixture, a platina plate was plunged into each vessel, and the circuit completed by a delicate galvanometer; not the slightest effect was produced; the plates were then put in communication with the poles of a common battery, and the amount of current which passed measured by means of a voltameter. No gas was evolved in the solutions, nor was any iron reduced, but the persulphate increased in quantity at one side, and the protosulphate at the other. When 80 measures of gas were collected, the battery was removed, and the plates being connected by the galvanometer as at the beginning of the experiment, a powerful current was produced in a direction the reverse of that of the battery; the effect was the same whether the same or fresh plates were used, and if they were simply washed with water, they might be moved from one vessel to the other, without producing the slightest effect on the current, provided their connexion with the galvanometer was also changed. The arrangement was again connected with the battery, in such a manner that the current should move in the solutions in the opposite direction to the former battery current, 80 measures of gas were again collected, and the battery being removed, not the slightest current was observed on connecting the plates with the galvanometer, but every thing was in the same state as at the commencement of the experiment. The power of the solution to produce the current gradually diminishes, but is not entirely destroyed until the second or return current becomes equal in amount to the first. The quantity of the return current cannot be measured correctly, without using the battery to enable it to pass quickly; because, from the extreme slowness of the action towards the end of the experiment, the solutions unavoidably mix, and thus cause great error in the amount. A similar experiment was tried with nitric acid, containing a large quantity of the lower oxides of nitrogen with precisely similar results.

Where the circuit is entirely metallic, but not homogeneous, we have also a return current; for the heat produced in a thermoelectric arrangement causes a current the reverse of that which produces it; but we cannot in this case determine the amount, from the impossibility of retaining the heat produced, and of preventing it from extending to those parts which ought to remain cold; the same may be the case also in a homogeneous circuit, but from the extremely low inten- 
sity, which is only equal to that necessary to cause the current to pass through it, we are unable to observe it.

From these and other observations of a similar kind, I believe it may be stated as a general law, that when a current passes through a series of conductors, it induces a state of things, capable of producing a current equal to itself in amount, and opposite in direction ; provided the changes produced are permanent.

This law can be proved to hold in all cases where a liquid forms part of the circuit, with the single exception of the case where two pieces of the same metal communicate by means of one of its salts; here the phænomena are the same as if the metallic circuit were complete. (Faraday.)

These results appear to show that there is something of the nature of a force transmitted through the circuit, and the phænomena of tension lend great support to this idea, for here we have bodies actually put in motion.

If now we suppose each chemical molecule to be capable of exerting an attractive force on every other molecule in its vicinity, the phænomena of the voltaic circuit are precisely what should result from such an attraction, and voltaic action appears to be chemical action under another form; the action in one case taking place between molecules in contact, or at extremely small distances, and in the other between those at a considerable and sensible distance.

If any number of molecules of different substances be placed near each other, and in such a state as to admit of their free motion, they arrange themselves so that their attractive forces produce a state of equilibrium, and till this state is attained the molecules are in a constrained condition.' Thus when chlorine, hydrogen and water are brought into contact, the hydrogen and chlorine unite to form hydrochloric acid, and this is the state of equilibrium. The mode in which this state is attained seems to be as follows:-(Fig. 1.) C(i) (O) ) atom of $\mathrm{Cl}$ unites with the $\mathrm{H}$ previously in combination with the $\mathrm{O}$ as water, while the $\mathrm{O}$ unites with the free $\mathrm{H}$, and $\mathrm{Cl} \mathrm{H}$ and $\mathrm{H} \mathrm{O}$ are formed; if, however, the $\mathrm{H}$ and $\mathrm{Cl}$ are at some distance from each other, as when separated by water, the (Fig. 2.) (A)(O)(B) action cannot take place, for the molecules cannot assume such an arrangement as would form a complete circuit, without which they cannot exert their attractions, but if $\mathrm{H}$ and $\mathrm{Cl}$ be united by a metal (Fig. 3.) 


\section{(H) $O(O)$ (H)}

the liquid, the circuit is completed, $\mathrm{H} \mathrm{Cl}$ is formed, and equilibrium restored. The attraction which was before exerted between $\mathrm{H}$ and $\mathrm{Cl}$ was unobserved on account of their extreme nearness, but is now continued through the whole length of the circuit, and we have thus the means of observing the phænomena to which it gives rise.

If $\mathrm{Cl}$ be the only free element, the molecules arrange them-

selves thus:-(Fig.4.) Co, the $\mathrm{Cl}$ and $\mathrm{H}$ unite, and the $\mathrm{O}$ is

set free; if in place of $\mathrm{Cl}$ and $\mathrm{O}$ being in contact at the moment of the evolution of $\mathrm{O}$, they are at some distance, the intervening space being occupied by a metal, we have the same phrnomena as in the first case, except, that the $\mathrm{O}$ finding nothing with which it can unite, is set free at the surface of the metal; the action in this case proceeds much more rapidly than when no metal is used, in consequence of the great attraction between the zincous and chlorous atoms of the platina, for the attraction throughout the circuit is equal to the most powerful exerted at any part of it. It is not necessary that the atoms acting in this manner should be elementary substances, for compound substances, such as cyanogen, many neutral salts and organic substances, act in the same manner.

The result of the action is the same, whether we simply mix the liquids, or form them into a voltaic circuit as above described. If, for example, we mix one equivalent of $\mathrm{Cl}$ and $\mathrm{Sn} \mathrm{Cl}$, one equivalent of $\mathrm{Sn} \mathrm{Cl}_{2}$ is formed. If, instead of mixing the solutions, we place them in porous vessels, immersed in hydrochloric acid, and conrect them by a slip of platina, the result is the same as before, and the quantity of acid remains the same, having served merely as the means of connecting the solutions, and might be dispensed with, were it not, that the unavoidable mixing which takes place when the solutions are in contact, renders the result very unsatisfactory. If, in place of the above-mentioned solutions, we substitute the per- and protochloride of iron, the formation of perand protochloride continues till the quantity of these salts is equal in the two vessels.

It thus appears that the result is the same as would be produced by diffusion.

The action as before mentioned is similar with $\mathrm{H}$ and $\mathrm{Cl}$; with $\mathrm{Cl}$ and $\mathrm{HO}, \mathrm{HS}, \mathrm{HI}, \mathrm{KO}, \mathrm{KS}$, KI, we have a chloride 
of hydrogen, or of the metal formed, and the combined radical is evolved. This law is a general one, and holds good equally in ordinary chemical action; but here the result is modified from the circumstances in which the action takes place. Thus when $\mathrm{Cl}$ is added to $\mathrm{KO}$, no oxygen is evolved; but this disappearance of the oxygen is entirely a secondary result; the oxygen at the moment of its evolution is in contact with $\mathrm{Cl}$ and; $\mathrm{KO}$, by which it is absorbed, giving rise to the chlorate of potash : but no such result can occur in the voltaic arrangement; for the oxygen, at the moment of its evolution, is not in contact with $\mathrm{Cl}$, and therefore appears as gas. Another difference between voltaic and chemical action is, that in the former, substances unite which are without action on each other when simply mixed, for example-oxygen and hydrogen; but this arises from the powerful attraction of the molecules of the platina, re-acting on the hydrogen and oxygen. The intensity is thus raised to the point necessary to cause combination.

It will now be evident why no current should result from the union of an acid and an alkali; thus if hydrochloric acid and potash be in contact, we have simply an exchange of the

elements (Fig. 5.) (B)(B)

liberated $\mathrm{O}$ unites with the $\mathrm{H}$ of the hydrochloric acid, and the current is confined within the four elements, which cannot in this case be separated; the same is true of sulphuric acid, substituting $\mathrm{SO}_{4}$ for $\mathrm{Cl}$. Nitric, chromic and several other acids are capable of acting in a very different manner from this. The whole atom of acid $\mathrm{NO}_{6}+\mathrm{H}$ is capable of acting in the same manner as $\mathrm{Cl}$, uniting with the basyle of the substance in contact with it, and evolving the radical, as in the pile of nitric acid and potash of Becquerel, but in this case the acid is reduced to the state of peroxide of nitrogen or nitric oxide. The increase in the intensity of the action, by using potash in contact with nitric acid, seems to be due to the affinity of the potash, for an additional quantity of oxygen and the formation of peroxide of potassium, which is immediately decomposed by the water; on substituting caustic ba. rytes, no oxygen is evolved.

The clianges which take place when organic substances are arranged so that a current is formed, afford an interesting subject for inquiry, and it appears probable that many of the effects described as catalytic, are the result of actions of this nature; for it is not necessary that the substance connectPhil. Mag. S. 3. Vol. 22. No. 147. June 1843. 2 G 
ing the liquids should be a metal; any conducting substance will answer the same purpose; nor is it necessary that the substance should have a sensible size, for a single atom may produce a new arrangement of the molecules of the substance with which it is in contact, as in the case of platina with oxygen and hydrogen, when these substances are mixed, by the intensity of the attraction of its atoms, and this arrangement will depend on that of the substance causing decomposition; the arrangement of the atoms composing the ordinary molecules being similar in both.

It would thus appear that voltaic action is nothing more than chemical action taking place in circumstances that enable us to observe many of the phænomena to which it gives rise, and which we have no means of observing in ordinary cases; and that chemical action is the result of the tendency of the molecules to arrange themselves in a state of equilibrium, in the same manner as ordinary mechanical forces.

LXXI. On the Combination of prolonged direct luminous Impressions on the Retina with their complementary Impressions. By Sir David Brewster, K.H., D.C.L., F.R.S., and V.P.R.S. Edin.*

T $\mathrm{T}$ is well known that when we have looked steadily at an object for some time, and then shut our eyes, the object continues visible, and of its natural colour, or the impression of it is prolonged on the retina during the third part of a second; and it is equally well known that if the object is coloured and pretty luminous, it will appear in its accidental or complementary colours after the third of a second has elapsed. This last phænomenon is easily seen, but I have met with many persons who have never seen distinctly the first phænomenon, unless in experiments such as those exhibited by the thaumatrope, and similar pieces of apparatus.

In making some of these experiments in the morning before the eye has had its sensibility diminished by exposure to light, I have observed a singular combination of these two phænomena, which I believe has not been previously noticed.

If, when our eyes have been for a few minutes shut, we open them and look steadily at the pattern of a carpet, suppose a red pattern upon a green ground, and then suddenly shut our eyes, we shall see the red pattern upon a pinkish-green ground, the red being very deep and approximating to black.

* Communicated by the Author. 